\title{
Coronavirus disease 2019 (COVID-19) pneumonia incidentally detected on coronary CT angiogram: a do-not-miss diagnosis
}

\author{
Shima Behzad ${ }^{1} \cdot$ Erik Velez $^{2} \cdot$ Mohammad Hosein Najafi $^{1} \cdot$ Ali Gholamrezanezhad $^{2}$ (D)
}

Received: 28 April 2020 / Accepted: 25 May 2020 / Published online: 9 June 2020

(C) American Society of Emergency Radiology 2020

\begin{abstract}
Coronary CT angiograms are commonly performed for the evaluation of coronary artery disease and coronary arterial anatomy. However, extracardiac findings are frequently detected on these examinations and often can explain patients' underlying symptoms, having a significant impact on patient management. Here in, we discuss three cases of incidentally detected novel COVID19-infected pneumonia (NCIP). This case series highlights the image findings in NCIP and emphasizes the importance of evaluating all organs in the field of view on coronary CT angiograms. In addition, with the ongoing outbreak of COVID-19 and exponentially increasing incidence throughout the world, this report stresses the need for including NCIP in the differential diagnosis of patients with typical image findings in at-risk populations, as early diagnosis is crucial for appropriate patient management and post-exposure recommendations.
\end{abstract}

Keywords COVID-19 · Novel COVID-19-infected pneumonia · Coronavirus · Coronary · CT angiography · Pneumonia · Atherosclerosis

\section{Introduction}

Coronary heart disease (CHD) is a leading cause of morbidity and mortality around the world, with the use of myocardial perfusion imaging (MPI) utilizing SPECT and coronary CT angiogram (cCTA) increasing significantly as a means for non-invasively evaluating patients. However, while MPI is performed for assessing myocardial ischemia, coronary artery stenosis, and coronary arterial anatomy, the incidental detection of extracardiac findings is common. A wide array of incidentally detected pathologies have been reported in the literature, including breast cancer, multiple myeloma, cirrhosis, interstitial lung disease, and pneumonia [1-6]. Extracardiac findings can often be the source of a patient's presumed cardiac symptoms and it is vital for physicians interpreting examinations to evaluate and report said findings. In this article, we report three cases of confirmed COVID-19

Ali Gholamrezanezhad

ali.gholamrezanezhad@med.usc.edu

School of Medicine, Azad University, Tehran, Iran

2 Department of Radiology, Keck School of Medicine, University of Southern California (USC), 1500 San Pablo Street, Los Angeles, CA 90033, USA infections incidentally detected on coronary dedicate on coronary CT angiography.

\section{Case series}

The first patient is a 60 -year-old male with a history of coronary artery bypass graft (CABG) surgery 14 years ago, who presented to cardiology with complaints of chest pain, loss of appetite, nausea, and malaise for 5 days without a reported fever or shortness of breath. His past medical history was also significant for diabetes mellitus type 2 and hypercholesterolemia. He underwent a cCTA which demonstrated geographic areas of basilar and peripheral predominant ground glass opacities with subpleural sparing (Fig. 1a). The patient's coronary artery bypass grafts were patent without significant stenosis (Fig. 1b). Shortly after the cCTA, the patient was admitted to the hospital, isolated, and diagnosed with COVID-19 pneumonia. The patient rapidly deteriorated in the hospital, developing acute respiratory distress syndrome (ARDS) and currently is in the intensive care unit (ICU) undergoing treatment.

The second patient is a 55-year-old male with no significant past medical history or complaints who presented for cCTA as part of a work-up for an underlying cardiac 
Fig. 1 a CT angiogram demonstrates patchy peripheral predominant ground glass airspace opacity in the dependent lung segment. There was no evidence of pleural effusion, cavitation, or lymphadenopathy. Findings are typical of COVID19 pneumonia, and should be included in the differential in geographic areas of disease outbreaks. b Coronary artery bypass grafts are patent without significant stenosis
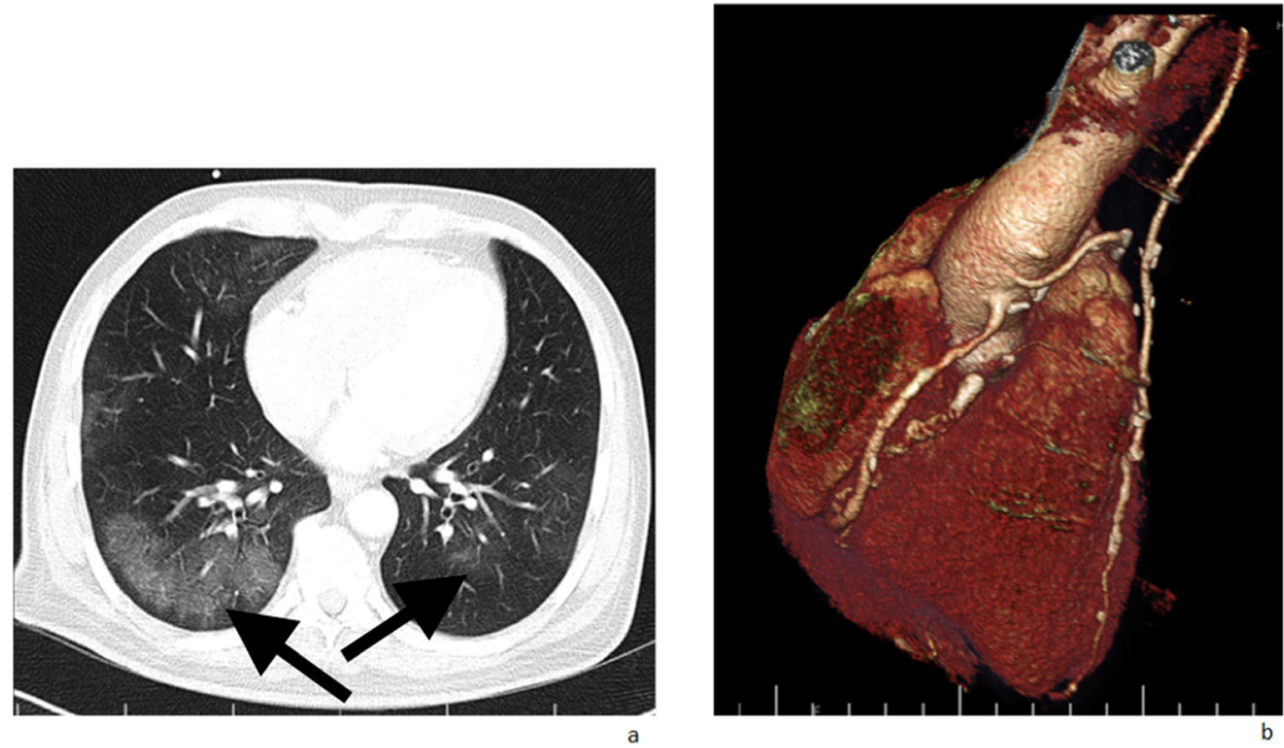

arrhythmia. The cCTA demonstrated a patchy ground glass opacity within the right lung base (Fig. 2). The patient subsequently became symptomatic with a fever and cough approximately $48 \mathrm{~h}$ after the initial scan, and tested positive for COVID-19 on a real-time polymerase chain reaction (RTPCR) test.

The third patient is a 40-year-old female who presented with a few days of shortness of breath and dyspnea on exertion with mild associated chest pain. The patient had no significant past medical history and denied any cough or fevers. Due to the concern for exertional chest pain, the patient underwent a cCTA which demonstrated patent coronary arteries and multifocal, peripheral, lower lobe predominant ground glass

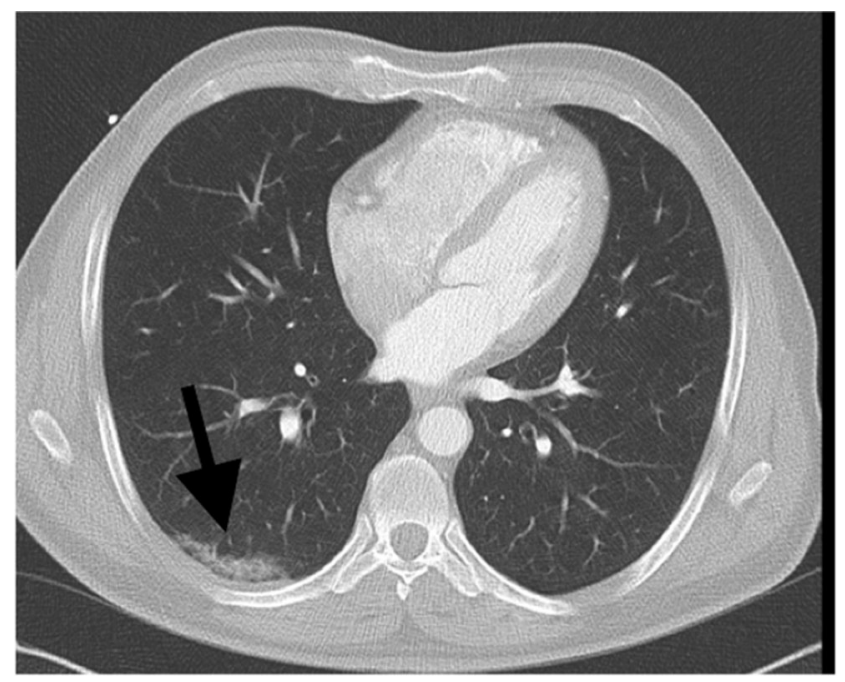

Fig. 2 Subpleural focal area of ground glass opacification was incidentally identified at the right lung base without consolidation, cavitation, pleural effusion, or lymphadenopathy. The patient was initially asymptomatic, but developed upper respiratory tract symptoms approximately $48 \mathrm{~h}$ after the scan and was subsequently diagnosed with COVID-19 by RT-PCR opacities, typical of reported CT findings of COVID-19 infection (Fig. 3).

\section{Discussion}

COVID-19 was first reported in December 2019 in Wuhan City, China, as a lower respiratory tract illness of unknown origin. Since then, the virus has rapidly spread with over four million confirmed cases of COVID-19 worldwide as of May 17, 2020 [7]. Although China has been the main country affected by the virus, 64 other countries had confirmed cases of COVID-19, including numerous cases in the United States. Presentations of COVID-19 can vary widely, from completely asymptomatic to severe respiratory syndrome and death. The most common reported symptoms at presentation are fever (43.8\% on admission, $88.7 \%$ during hospitalization), dry cough, fatigue, sputum production, shortness of breath, sore throat, headache, myalgia/arthralgia, chills, nausea/vomiting, nasal congestion, diarrhea, hemoptysis, and conjunctival congestion [8]. Patients infected with the virus typically develop signs and symptoms after a mean incubation period of 5-6 days [9-11]. However, the utilization of fever and other typical clinical manifestations of COVID-19 infection, particularly in the very early stages of infection, have been associated with high false-negative rates. Thus, the absence of typical clinical features of COVID-19 is insufficient to exclude the diagnosis in the early stages [12].

In this article, we report three cases with COVID-19 found incidentally during coronary CT angiography. Patients were referred by their cardiologists for cCTAs due to suspected coronary heart disease, with no clinical suspicion of pneumonia at the time. This highlights the non-specific presentations of COVID-19 infections and difficulty of making the 
Fig. 3 a-c Multiple bilateral, peripheral, and basilar predominant scattered ground glass opacities are noted. No pleural effusion, consolidation, or lymphadenopathy were detected. d The coronary arteries demonstrate no significant atherosclerotic or stenotic disease
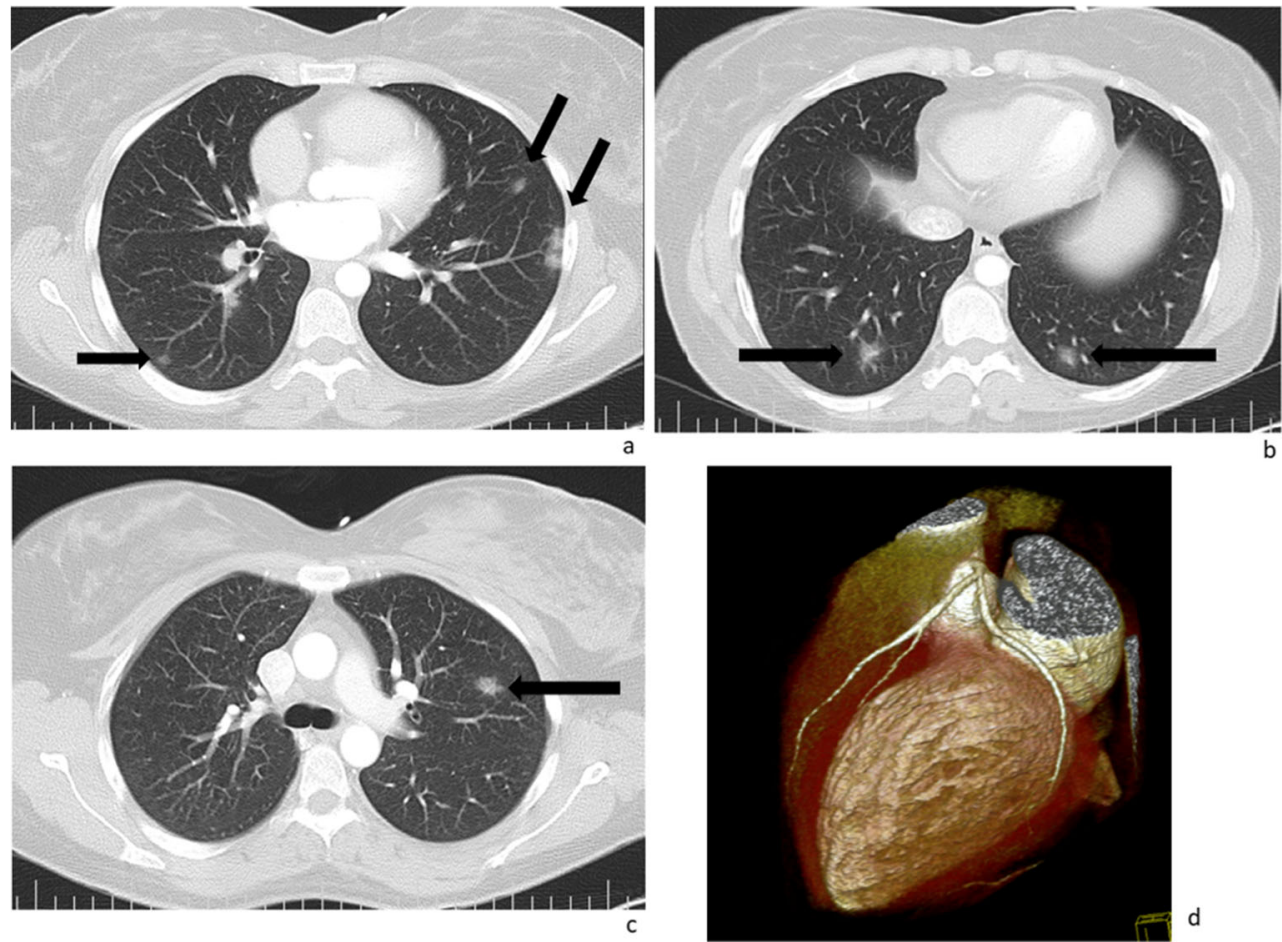

diagnosis on a clinical basis. The typical findings of COVID19 infection on CT are bilateral peripheral and basilar predominant ground glass opacities and consolidations with extensive geographic distributions [13-17]. Lymphadenopathy and pleural effusions are rare in COVID-19 infections, and are suggestive of an alternative diagnosis. In a study by Pan et al. evaluating the time course of lung changes on $\mathrm{CT}$ in patients diagnosed with COVID-19 pneumonia, early CT findings in patients included no findings (17\%), a focal area of ground glass or consolidation (42\%), and multilobe opacities $(42 \%)$, with a peripheral predominance for airspace opacities [15]. The patients in our case series demonstrated similar early CT findings, underlining the importance of including COVID-19 on the differential in at-risk patients with incidentally detected suspicious patterns of airway disease. Furthermore, the typical demographic of patients undergoing myocardial perfusion imaging are elderly with underlying medical co-morbidities. These patients have shown to be at the highest risk for developing complications related to COVID-19 infection, with increased rates of ICU admissions and mortality $[18,19]$, stressing the need for early recognition and treatment of COVID-19 in this high-risk demographic.

The detection of incidental extracardiac findings on cCTAs is common and the evaluation and reporting of extracardiac findings should be performed on every myocardial perfusion study [20-22]. In a review of the literature discussing the incidental extracardiac findings on cCTA, a total of 13 articles were found including a total of 13,995 patients. Incidental extracardiac findings were detected in 4286 of these patients (30.6\%) encompassing a wide array of pathologies, including the diagnosis of lung, adrenal, hepatic, and osseous malignancies (Table 1). In addition, similar rates of extracardiac findings have been reported in cardiac magnetic resonance imaging (cMRI) [34] and myocardial perfusion SPECT imaging [35]. A recent publication by Ai et al. demonstrated chest CT to have a higher sensitivity for the diagnosis of COVID-19 than initial RT-PCR tests, suggesting chest CT may be used as a primary method for diagnosis in epidemic areas [36]. This is likely in part due to the reported low sensitivity of the RTPCR test for COVID-19, ranging around 60-70\%, requiring multiple tests to confidently rule out the diagnosis [37]. Thus, knowledge of the typical and early imaging findings of COVID-19 infections is crucial to ensure appropriate early diagnosis.

\section{Conclusion}

The interpretation of a coronary CT angiogram should not be limited to the evaluation of coronary arteries. With the growing incidence of COVID-19, radiologists and cardiologists interpreting cCTAs should be aware of the imaging features of the SARS-CoV-2 infection. In epidemic areas, COVID-19 should be included in the differential diagnosis in patients with suspicious imaging features, for which constant vigilance is vital. Although the full-field-of-view reconstructions are not incorporated in CCTA protocols of many imaging centers, they should be routinely reviewed as a part of image interpretation. Multiple prior studies have emphasized the importance of full-field-of-view images in identifying major extracardiac 
Table 1 Incidental extracardiac findings in coronary CT angiographic studies

\begin{tabular}{|c|c|c|c|c|}
\hline Authors & $\begin{array}{l}\text { Year of } \\
\text { publication }\end{array}$ & $\begin{array}{l}\text { No. of } \\
\text { patients }\end{array}$ & $\begin{array}{l}\text { No. of } \\
\text { findings }\end{array}$ & Incidental extracardiac findings \\
\hline $\begin{array}{l}\text { Christoph } 1 . \\
\text { Lee [23] }\end{array}$ & 2010 & 151 & 102 & $\begin{array}{l}\text { Pulmonary nodule } \geq 4 \mathrm{~mm} \text {, interstitial lung disease, equivocal liver lesion, lung consolidation, } \\
\text { gynecomastia, cholelithiasis, compressed bronchus, marked mediastinal lymphadenopathy, } \\
\text { pleural effusion, marked ascites, moderate hiatal hernia, multinodular goiter, pulmonary } \\
\text { nodule }<4 \mathrm{~mm} \text {, calcified granulomata, fissure opacity or atelectasis, benign hepatic cyst, } \\
\text { simple renal cyst, small hiatal hernia, pleural calcification, benign adrenal adenoma, pectus } \\
\text { deformity, hamartoma in the lung }\end{array}$ \\
\hline $\begin{array}{c}\text { Jay Koonce } \\
{[24]}\end{array}$ & 2008 & 1764 & 507 & $\begin{array}{l}\text { Aneurysm, pulmonary embolism, adenopathy, cyst, mass, nodules, pneumonia, interstitial } \\
\text { disease, airways disease, atelectasis, emphysema, pleural effusion and plaque, breast mass, } \\
\text { thyroid mass, bone metastasis, hepatic cyst, indeterminate liver, liver mass, adrenal mass, } \\
\text { miscellaneous findings }\end{array}$ \\
\hline $\begin{array}{l}\text { Vikram } \\
\text { Venkatesh, } \\
\text { MD [25] }\end{array}$ & 2010 & 80 & 67 & $\begin{array}{l}\text { Lung/mediastinum: suspicious pulmonary nodule, pulmonary fibrosis, benign nodule/granuloma } \\
\text { bulla, pleural plaques atelectasis/scar lymph nodes } \\
\text { Liver: indeterminate lesions, cyst, steatosis } \\
\text { Kidney: indeterminate lesion, cyst, calculi, atrophy } \\
\text { Gallbladder: calculi } \\
\text { Spleen: granuloma } \\
\text { Vascular: anatomic variant, ectatic/atheromatous aorta } \\
\text { Gastrointestinal: hiatus hernia } \\
\text { Adrenal: indeterminate lesion, adenoma }\end{array}$ \\
\hline $\begin{array}{l}\text { Olga Lazoura, } \\
\text { MD [26] }\end{array}$ & 2010 & 1044 & 729 & $\begin{array}{l}\text { Abdominal: hepatic steatosis, liver cyst, liver hemangioma, liver echinococcus cyst, calcified } \\
\text { liver granuloma, calcified splenic granuloma, ascites, abdominal aortic aneurysm, liver mass } \\
\text { Thoracic: emphysema, hiatus hernia, calcified lung granuloma, bone hemangioma, calcified } \\
\text { lymph nodes, bronchiectasis, remote fracture, substernal thyroid, pulmonary nodule, thoracic } \\
\text { adenopathy, pleural effusion, atelectasis, consolidation/GGO, pleural thickening, mediastinal } \\
\text { mass lesions, interstitial lung disease, ascending aortic aneurysm, dilated aortic root, } \\
\text { pulmonary hypertension, pulmonary embolus }\end{array}$ \\
\hline $\begin{array}{l}\text { Iman Aglan } \\
{[27]}\end{array}$ & 2009 & 542 & 391 & $\begin{array}{l}\text { Aorta: ascending aortic aneurysm, ascending aortic ectasia, atherosclerosis, atheroma, } \\
\text { supradiaphragmal kinking } \\
\text { Pulmonary vessels: pulmonary artery ectasia, supernumerary pulmonary vein (“top roof vein") } \\
\text { Pleura: effusion, nodular thickening } \\
\text { Lung parenchyma: infiltrate, post-inflammatory changes, atypical pneumonia, intrapulmonary } \\
\text { non-specific nodules, calcified/non-calcified granuloma, central bronchial neoplasm, } \\
\text { emphysema, dystelectasis } \\
\text { Bronchi: ectasia, wall thickening, indeterminate intraluminal structure } \\
\text { Lymph node: lymphadenopathy, calcification } \\
\text { Liver: steatosis hepatis, non-specific hypodense liver lesion, cyst } \\
\text { Gallbladder: cholecystolithiasis } \\
\text { Spleen: calcification } \\
\text { Miscellaneous: gastric bulging and mucosal hypertrophy, axial hiatal hernia, severe } \\
\text { diaphragmatic elevation }\end{array}$ \\
\hline $\begin{array}{l}\text { Pow-Li chia } \\
\text { [28] }\end{array}$ & 2009 & 1061 & 103 & $\begin{array}{l}\text { Liver tumors, cysts, and hemangiomas; hepatic steatosis; pneumobilia; pulmonary nodules; } \\
\text { emphysema; interstitial lung disease; histiocytosis; pneumonia, including tuberculosis; pleural } \\
\text { effusion; pulmonary edema; aortic aneurysms, pulmonary embolism; ascites; breast cancer; } \\
\text { adrenal hyperplasia; lymphoma }\end{array}$ \\
\hline $\begin{array}{l}\text { Sam J. Lehman } \\
\text { [29] }\end{array}$ & 2009 & 395 & 205 & $\begin{array}{l}\text { Lungs: non-calcified pulmonary nodule, calcified pulmonary nodule, pulmonary infiltrate, } \\
\text { emphysema, atelectasis, pleural effusion, enlarged hilar or mediastinal lymph node, pneumo- } \\
\text { thorax } \\
\text { Abdomen: liver cyst, contrast-enhancing liver lesion, fatty liver, hiatus hernia, contrast-enhancing } \\
\text { splenic lesion, gallstones } \\
\text { Aorta: aneurysm, dissection, penetrating aortic ulcer } \\
\text { Miscellaneous: hemangioma of the spinal column, thyroid mass, chest wall mass, hemangioma }\end{array}$ \\
\hline $\begin{array}{l}\text { Jin Woo Kim } \\
\text { [30] }\end{array}$ & 2009 & 254 & 282 & $\begin{array}{l}\text { Lungs and mediastinum: pulmonary nodule, consolidation/ground glass opacity, interstitial lung } \\
\text { disease, emphysema, bronchiectasis, fibrotic scar/air cyst, pleural thickening/calcification, } \\
\text { mediastinal mass/lymphadenopathy, pleural effusion } \\
\text { Aorta: aortic aneurysm/dissection }\end{array}$ \\
\hline $\begin{array}{l}\text { Yoshiyoki } \\
\quad \text { Kawano } \\
{[31]}\end{array}$ & 2007 & 617 & 149 & $\begin{array}{l}\text { Lung, thyroid and hepatic cancer, post-inflammatory lung nodules, hepatic cysts/hemangiomas, } \\
\text { benign thyroid tumors, mediastinal lymphadenopathies, benign mammary gland tumors, } \\
\text { esophageal submucosal tumor }\end{array}$ \\
\hline
\end{tabular}


Table 1 (continued)

\begin{tabular}{lllll}
\hline Authors & $\begin{array}{l}\text { Year of } \\
\text { publication }\end{array}$ & $\begin{array}{l}\text { No. of } \\
\text { patients }\end{array}$ & $\begin{array}{l}\text { No. of } \\
\text { findings }\end{array}$ & Incidental extracardiac findings \\
\hline $\begin{array}{c}\text { Jeffrey Mueller } \\
\text { [32] }\end{array}$ & 2007 & 259 & 51 & $\begin{array}{c}\text { Pulmonary nodule pneumonia, large mucous plug, pulmonary embolism, aortic ulcer or } \\
\text { aneurysm, adrenal mass, moderate pleural effusion, sternal dehiscence, mediastinitis, } \\
\text { sarcoidosis, pulmonary hypertension, moderate-sized pneumothorax }\end{array}$ \\
$\begin{array}{c}\text { Sabine Haller } \\
\text { [33] }\end{array}$ & 2006 & 166 & 36 & $\begin{array}{c}\text { Emphysema, hernia, lymphadenopathy, aortic aneurysm, arteria lusoria, bronchiectasis, nerve } \\
\text { root cyst, pleural calcification, severe spondylosis, pulmonary fibrosis, bronchial carcinoma, } \\
\text { pneumonia, pulmonary emboli, benign pulmonary mass }\end{array}$ \\
\hline
\end{tabular}

findings $[38,39]$. Hence, we strongly recommend the inclusion of full-field-of-view images in CCTA protocols in daily practice, as this may lead to the detection of crucial noncardiac pathologies. Very high clinical index of suspicion and a very low threshold for clinical and paraclinical screening and diagnostic testing, such as PCR and CT chest, allows earlier recognition, detection, and treatment of this potentially life-threatening and devastating disease and can help ensure appropriate post-exposure precautions are implemented.

\section{Compliance with ethical standards}

Conflict of interest The authors declare that they have no conflict of interest.

\section{References}

1. Bhambhvani P, Dubovsky E, Nath H, Heo J, Ami Iskandrian M (2010) Unusual incidental findings by SPECT myocardial perfusion imaging and CT in the same patient. J Nucl Cardiol 17(5):937

2. García-Talavera P, Olmos R, Sainz-Esteban A, Ruiz M, González M, Gamazo C (2013) Evaluation by SPECT-CT of an incidental finding of a thymoma and breast cancer in a myocardial perfusion SPECT with 99mTc-MIBI. Rev Esp Med Nucl Imagen Mol (Engl Ed) 32(4):260-262

3. Farag AA, Patel H, Bhambhvani P, Hage FG (2017) Incidental detection of abnormal $99 \mathrm{~m} \mathrm{Tc}$-sestamibi uptake in the sternum and ribcage from multiple myeloma by SPECT myocardial perfusion imaging. J Nucl Cardiol 24(4):1445-1446

4. Ghaedian T, Mortazavi S, Haghighatafshar M (2015) Multiple myeloma and abdominal aortic aneurysm on myocardial perfusion raw images. Clin Nucl Med 40(11):e526-e527

5. Husmann $L$ et al (2009) Prevalence of noncardiac findings on low dose 64-slice computed tomography used for attenuation correction in myocardial perfusion imaging with SPECT. Int J Cardiovasc Iimaging 25(8):859

6. Lindsay AC, Sriharan M, Lazoura O, Sau A, Roughton M, Jabbour RJ, di Mario C, Davies SW, Moat NE, Padley SPG, Rubens MB, Nicol ED (2015) Clinical and economic consequences of noncardiac incidental findings detected on cardiovascular computed tomography performed prior to transcatheter aortic valve implantation (TAVI). Int J Cardiovasc limaging 31(7):1435-1446

7. WHO (2020) WHO coronavirus disease (COVID-19) dashboard. Available: https://covid19.who.int/

8. Guan W-j, Ni ZY, Hu Y, Liang WH, Ou CQ, He JX, Liu L, Shan H, Lei CL, Hui DSC, du B, Li LJ, Zeng G, Yuen KY, Chen RC, Tang CL, Wang T, Chen PY, Xiang J, Li SY, Wang JL, Liang ZJ, Peng
YX, Wei L, Liu Y, Hu YH, Peng P, Wang JM, Liu JY, Chen Z, Li G, Zheng ZJ, Qiu SQ, Luo J, Ye CJ, Zhu SY, Zhong NS, China Medical Treatment Expert Group for Covid-19 (2020) Clinical characteristics of coronavirus disease 2019 in China. N Engl J Med 382:1708-1720

9. Kooraki S, Hosseiny M, Myers L, Gholamrezanezhad A (2020) Coronavirus outbreak: what the Department of Radiology should know. J Am Coll Radiol

10. Hosseiny M, Kooraki S, Gholamrezanezhad A, Reddy S, Myers L (2020) Radiology perspective of coronavirus disease 2019 (COVID-19): lessons from severe acute respiratory syndrome and Middle East respiratory syndrome. Am J Roentgenol 1-5

11. Behzad S, Aghaghazvini L, Radmard AR, Gholamrezanezhad A. Extrapulmonary manifestations of COVID-19: Radiologic and clinical overview [published online ahead of print, 2020 May 18]. Clin Imaging. 2020;66:35-41. https://doi.org/10.1016/j.clinimag.2020. 05.013

12. Salehi S, Abedi A, Balakrishnan S, Gholamrezanezhad A (2020) Coronavirus disease 2019 (COVID-19): a systematic review of imaging findings in 919 patients, (in eng). AJR Am J Roentgenol 1-7

13. Kanne JP, Little BP, Chung JH, Elicker BM, Ketai LH (2020) Essentials for radiologists on COVID-19: an update-Radiology Scientific Expert Panel. Radiology 200527

14. Bernheim A et al (2020) Chest CT Findings in coronavirus disease19 (COVID-19): relationship to duration of infection, (in eng). Radiology 200463

15. Pan F et al (2020) Time course of lung changes on chest CT during recovery from 2019 novel coronavirus (COVID-19) pneumonia, (in eng). Radiology 200370

16. Hosseiny M, Kooraki S, Gholamrezanezhad A, Reddy S, Myers L (2020) Radiology perspective of coronavirus disease 2019 (COVID-19): lessons from severe acute respiratory syndrome and Middle East respiratory syndrome. Am J Roentgenol 214(5):10781082

17. Kooraki S, Hosseiny M, Myers L, Gholamrezanezhad A (2020) Coronavirus outbreak: what the Department of Radiology should know. J Am Coll Radiol 447-451

18. Yang $X$ et al Clinical course and outcomes of critically ill patients with SARS-CoV-2 pneumonia in Wuhan, China: a single-centered, retrospective, observational study. Lancet Respir Med

19. Wang D et al (2020) Clinical characteristics of 138 hospitalized patients with 2019 novel coronavirus-infected pneumonia in Wuhan, China. JAMA

20. Assadi M, Velez E, Najafi MH, Gholamrezanezhad A (Apr 2019) The need for standardization of nuclear cardiology reporting and data system (NCAD-RADS): learning from coronary artery disease (CAD), breast imaging (BI), liver imaging (LI), and prostate imaging (PI) RADS, (in eng). J Nucl Cardiol 26(2):660-665

21. Gholamrezanezhad A, Mirpour S (2007) An important but easily forgettable review: extracardiac activity in myocardial perfusion scans. Int J Cardiovasc Imaging 23(2):207-208 
22. Lee CI, Tsai EB, Sigal BM, Plevritis SK, Garber AM, Rubin GD (Jun 2010) Incidental extracardiac findings at coronary CT: clinical and economic impact, (in eng). AJR Am J Roentgenol 194(6): $1531-1538$

23. Lee CI, Tsai EB, Sigal BM, Plevritis SK, Garber AM, Rubin GD (2010) Incidental extracardiac findings at coronary CT: clinical and economic impact. Am J Roentgenol 194(6):1531-1538

24. Koonce J, Schoepf JU, Nguyen SA, Northam MC, Ravenel JG (2009) Extra-cardiac findings at cardiac CT: experience with 1, 764 patients. Eur Radiol 19(3):570-576

25. Venkatesh V, You JJ, Landry DJ, Ellins ML, Sheth T (2010) Extracardiac findings in cardiac computed tomographic angiography in patients at low to intermediate risk for coronary artery disease. Can Assoc Radiol J 61(5):286-290

26. Lazoura O, Vassiou K, Kanavou T, Vlychou M, Arvanitis DL, Fezoulidis IV (2010) Incidental non-cardiac findings of a coronary angiography with a 128-slice multi-detector CT scanner: should we only concentrate on the heart? Korean J Radiol 11(1):60-68

27. Aglan I, Jodocy D, Hiehs S, Soegner P, Frank R, Haberfellner B, Klauser A, Jaschke W, Feuchtner GM (2010) Clinical relevance and scope of accidental extracoronary findings in coronary computed tomography angiography: a cardiac versus thoracic FOV study. Eur J Radiol 74(1):166-174

28. Chia P-L, Kaw G, Wansaicheong G, Ho K-T (2009) Prevalence of non-cardiac findings in a large series of patients undergoing cardiac multi-detector computed tomography scans. Int J Cardiovasc Iimaging 25(5):537-543

29. Lehman SJ, Abbara S, Cury RC, Nagurney JT, Hsu J, Goela A, Schlett CL, Dodd JD, Brady TJ, Bamberg F, Hoffmann U (2009) Significance of cardiac computed tomography incidental findings in acute chest pain. Am J Med 122(6):543-549

30. Kim JW et al (2009) Incidental extracardiac findings at cardiac CT angiography: comparison of prevalence and clinical significance between precontrast low-dose whole thoracic scan and postcontrast retrospective ECG-gated cardiac scan. Int J Cardiovasc limaging 25(1):75

31. Kawano Y, Tamura A, Goto Y, Shinozaki K, Zaizen H, Kadota J (2007) Incidental detection of cancers and other non-cardiac abnormalities on coronary multislice computed tomography. Am J Cardiol 99(11):1608-1609

32. Mueller J, Jeudy J, Poston R, White CS (2007) Cardiac CT angiography after coronary bypass surgery: prevalence of incidental findings. Am J Roentgenol 189(2):414-419

33. Haller S, Kaiser C, Buser P, Bongartz G, Bremerich J (2006) Coronary artery imaging with contrast-enhanced MDCT: extracardiac findings. Am J Roentgenol 187(1):105-110

34. Gravina $M$ et al (2017) Incidental extracardiac findings and their characterization on cardiac MRI. Biomed Res Int 2017

35. Gholamrezanezhad A, Moinian D, Eftekhari M, Mirpour S, Hajimohammadi H (2006) The prevalence and significance of increased gastric wall radiotracer uptake in sestamibi myocardial perfusion SPECT. Int J Cardiovasc Iimaging 22(3-4):435-441

36. Li YC, Bai WZ, Hashikawa T (2020) The neuroinvasive potential of SARS-CoV2 may be at least partially responsible for the respiratory failure of COVID-19 patients. J Med Virol

37. Fang Y et al (2020) Sensitivity of chest CT for COVID-19: comparison to RT-PCR, (in eng). Radiology 200432

38. Kim TJ, Han DH, Jin KN, Lee KW (2010) Lung cancer detected at cardiac CT: prevalence, clinicoradiologic features, and importance of full-field-of-view images. Radiology 255

39. Northam M, Koonce J, Ravenel JG (2008) Pulmonary nodules detected at cardiac CT: comparison of images in limited and full fields of view. Am J Roentgenol 191(3):878-881

Publisher's note Springer Nature remains neutral with regard to jurisdictional claims in published maps and institutional affiliations. 